\title{
A arte como ferramenta no ensino de Ciências da Natureza nas séries iniciais do Ensino Fundamental
}

\author{
Luísa Brum Prestes* \\ Daniele Muniz de Oliveira** \\ Andrea Anilda Hoffmann da Rocha*** \\ Victor João da Rocha Maia Santos ${ }^{* * *}$
}

\begin{abstract}
Resumo:
O presente artigo visa a apresentar as conclusões que foram obtidas com o trabalho realizado na oficina "Fazendo Arte e Aprendendo Ciências" no Colégio de Aplicação da Universidade Federal do Rio Grande do Sul. Participaram da oficina dez alunos dos anos iniciais do Ensino Fundamental, lecionada por uma professora da instituição e duas alunas do Programa Institucional de Iniciação à Docência (PIBID), estudantes do curso de Licenciatura em Educação do Campo - Ciências da Natureza. Os instrumentos de pesquisa utilizados para a realização do trabalho foram: desenhos feitos pelos estudantes, fotos e os vídeos das práticas. As aulas foram planejadas a partir de temas de interesse dos alunos, partindo de atividades lúdicas envolvendo arte foi possível apresentar os conceitos científicos de forma mais leve, possibilitando ao aluno criar hipóteses e teorias do que estava acontecendo.
\end{abstract}

\section{Palavras-chave:}

Ciências da Natureza. Arte. Séries iniciais.

\section{Resumen:}

El propósito de este artículo es presentar las conclusiones obtenidas como un trabajo realizado en la oficina "Hacer arte y aprender ciencias" y no Colégio de Aplicação de la Universidade Federal do Rio Grande do Sul. Participará en el puesto durante unos dos años iniciado en la Escuela Primaria, leído por un profesor del instituto y dos estudiantes del Programa Institucional de Iniciação à Docência (PIBID), estudiantes de la Licenciatura en Educación en el Área - Ciencias Naturales. Los instrumentos de investigación utilizados para realizar el trabajo fueron: sueños feos, cabello, estudiantes, fotos y videos de prácticas. Como las aulas se planificaron en base a temas de interés durante dos años,

\footnotetext{
* Graduanda do Curso de Licenciatura em Educação do Campo - Ciências da Natureza pela Universidade Federal do Rio Grande do Sul (UFRGS). E-mail: luísabrump@gmail.com. ORCID iD: http://orcid.org/0000-0001-7434-3514.

** Graduanda do Curso de Licenciatura em Educação do Campo - Ciências da Natureza pela Universidade Federal do Rio Grande do Sul (UFRGS). E-mail: daniele.muniz@hotmail.com. ORCID iD: http://orcid.org/0000-0003-4933-2244.

*** Doutora em Química, pós-doutoranda em Química pela Universidade Federal do Rio Grande do Sul (UFRGS). E-mail: deiaahoffmann@gmail.com. ORCID iD: http://orcid.org/0000-0001-6870-3755.

**** Doutor em Educação em Ciências, professor de Química no CAp da Universidade Federal do Rio Grande do Sul (UFRGS). E-mail: victor.jrms@gmail.com. ORCID iD: http://orcid.org/0000-0003-2274-3756.
} 
en base a actividades lúdicas relacionadas con el arte, es posible presentar consejos científicos de una manera más ligera, lo que permite plantear hipótesis y teorías que estaban sucediendo.

\section{Palabras-clave:}

Ciencias de la Naturaleza. Arte. Serie inicial.

\section{Introdução}

O presente trabalho tem como finalidade apresentar os resultados adquiridos na Oficina de Ciências "Fazendo Arte e Aprendendo Ciências", utilizando a arte como ferramenta de ensino de Ciências da Natureza. A oficina foi realizada no laboratório de ciências do Colégio de Aplicação (CAp) da Universidade Federal do Rio Grande do Sul (UFRGS). A oficina foi oferecida como disciplina eletiva e teve a participação de alunos e alunas dos anos iniciais do Ensino Fundamental do CAp-UFRGS na modalidade multisseriada com alunos do $2^{\circ}$ ao $5^{\circ}$ ano, entre os 7 e 10 anos.

A disciplina foi ministrada pela professora de Química da instituição com o auxílio de duas alunas do curso de licenciatura em Educação do Campo - Ciências da Natureza da UFRGS, bolsistas do Programa Institucional de Iniciação à Docência (PIBID), da instituição. As oficinas ocorreram uma vez por semana nos dois últimos períodos da manhã (10h35min - 12h10min), após o horário de recreio dos estudantes.

Um dos objetivos da oficina foi de ensinar Ciências de forma lúdica utilizando a arte como ponte para esse ensino, para despertar o interesse dos estudantes pelo estudo das Ciências da Natureza e conduzir as crianças na conquista desse conhecimento. Os instrumentos de pesquisa utilizados foram os desenhos produzidos pelos alunos e alunas ao final de cada aula, a participação através da fala nas atividades antes do experimento e durante e após a conclusão das atividades e as anotações realizadas pelas bolsistas "pibidianas" ao longo do semestre em seus cadernos de campo, onde colocaram suas observações e notas para consulta posterior e registro das atividades.

As aulas foram planejadas a partir de temas de interesse dos alunos, buscando uma aula recreativa, leve, contemplando as diferentes faixas etárias. A partir das atividades lúdicas envolvendo arte foi possível apresentar os conceitos científicos de forma mais leve e fluída, possibilitando ao aluno criar hipóteses e teorias do que estava acontecendo, além de tornar a atividade mais atrativa. A arte foi representada das mais diversas formas, desde a escolha das cores dos experimentos, instrumentos utilizados para realização das atividades, a forma de registro (desenhos, escritas, pinturas e a fala), o trabalho em equipe e aprender a compartilhar os materiais. A arte é uma atividade humana que pode ser disposta de forma estética ou comunicativa, assim a fala, gestos, desenhos, escritas e canto são formas de se expressar artisticamente e muitas estavam presentes ao longo da oficina. A análise dos registros possibilitou a verificação da interação de todos os alunos com as atividades propostas, como também, diferentes formas de aprendizado e conhecimentos. A utilização da arte para ensinar conceitos das Ciências da Natureza se mostrou eficiente ao longo de todo o semestre.

\section{Contextualização do trabalho}

O Programa Institucional de Iniciação à Docência (PIBID), como consta no portal online da CAPES, visa melhorar e valorizar o estudante que está se formando como professor/ professora para se tornar um profissional ainda mais qualificado para atuar nas escolas. Entre os vários objetivos do programa estão listadas promover uma ponte entre o Ensino Superior e as escolas de educação básica, melhorando o ensino e incentivando os estudantes através de bolsas voluntárias ou remuneradas e inserir os estudantes dentro das realidades de funcionamento das escolas. O PIBID tem o objetivo de oportunizar novas experiências 
de formação, visando as melhores oportunidades de crescimento e aprendizado e qualificação e ainda auxiliando financeiramente os alunos/as alunas através das bolsas do programa.

As duas bolsistas do PIBID iniciaram suas atividades em setembro de 2018. As atividades realizadas com supervisão dos professores do PIBID proporcionaram momentos para que as estudantes se habituassem à rotina escolar, dentro de sala de aulas e em reuniões de planejamento de disciplinas eletivas nas áreas de química, física e biologia. Essa experiência possibilitou que as alunas se sentissem confortáveis e confiantes dentro da instituição para atuar como professoras.

\section{Metodologia}

O método de observação participante foi utilizado para a realização da coleta de dados para esse trabalho. Essa metodologia implica em saber utilizar de todos os sentidos, observar o grupo que está sendo pesquisado por um longo período e o resultado do trabalhador vai depender da sua relação com o grupo, como defende Valladares (2007). A oficina permitiu participação livre dos estudantes nas atividades, eles não eram obrigados a participar e se expressar da forma como as professoras solicitaram, assim os alunos utilizaram diferentes formas de expressão, por exemplo, o desenho. Para que toda essa liberdade pudesse ser dada aos alunos, no primeiro dia de oficina foi acordado com os estudantes: não cheirar, não tocar e não pôr os materiais na boca a não ser que fosse solicitado pelas professoras.

Os instrumentos de pesquisa foram os materiais produzidos pelos alunos e alunas ao final das aulas, fotos e filmagens capturadas pelas docentes e os cadernos das bolsistas "pibidianas", que constam as falas dos alunos durante as aulas, registros e observações das professoras e ainda relatos e análises realizadas em coletivo sobre as práticas. Os registros das atividades feitos pelos alunos ao final das aulas tinham a intenção de que os alunos passassem para o papel o que foi aprendido por eles ao longo daquela aula. O registro foi feito através das palavras, desenhos e rabiscos, utilizando folhas de ofício, lápis grafite, lápis de cor e canetas hidrocores e borrachas. Os diários das bolsistas foram utilizados para registrar as atividades que foram realizadas durante o período em que participaram do PIBID. Eles possuem mais de 40 folhas de anotações referentes às aulas da oficina, nele encontram-se os desafios, vitórias, frustrações e o passo a passo da construção das aulas e escolha das experiências, como defende Lewgoy e Arruda (2004), o caderno se torna um exercício acadêmico e auxilia na formação da identidade profissional do educador.

\section{A oficina}

A oficina "Fazendo Arte e Aprendendo Ciências", foi ofertada como disciplina eletiva no ano de 2019/2. A turma era composta por 10 alunos, do $2^{\circ}$ ao $5^{\circ}$ ano do Ensino Fundamental, com idades entre 7 e 10 anos. Sendo assim, a turma tinha alunos em processo de alfabetização e alunos já alfabetizados e a forma como isso foi trabalhado nas avaliações era que eles tinham liberdade para escolher a maneira como iriam se expressar. As avaliações entregues tinham escritas desenvolvidas, desenhos, frases e palavras soltas e muitas vezes os alunos pediam ajuda para escrever determinadas palavras como "Ciências" e "Experiências". As atividades realizadas em sala com as crianças eram testadas anteriormente e sempre pensadas através do interesse dos alunos e as experiências que eles diziam ter vontade de fazer. Entre os experimentos realizados estão: experimento com líquidos com diferentes densidades (óleo, água com corante alimentício, antiácido); Sangue de Unicórnio (suco de limão e/ou laranja, glitter comestível e açúcar); Mensagens secretas (uma solução básica, utilizando indicador de pH e uma solução ácida, que ao aproximar do fogo mostra a mensagem); Vulcão (mistura próxima a massa de pão, bicarbonato de sódio, corante e vinagre). Essas atividades eram coerentes com a idade das crianças, não apresentando adversidades e sempre foram retomadas as regras básicas de segurança num laboratório de ciências, como: não comer, não cheirar e não tocar sem a autorização das professoras. 
As aulas foram realizadas no Laboratório de Ciências do CAp-UFRGS, fora da rotina dos estudantes. O laboratório é uma sala ampla, onde no meio encontra-se uma mesa retangular (onde ocorreu a maioria dos experimentos) e na sua volta 9 mesas hexagonais, ao fundo uma bancada em forma de L, onde estavam expostos animais dentro de vidros, alguns animais empalhados e em uma das pontas da parede a pintura de uma árvore filogenética que da ponta de seus galhos estavam pintadas diversas espécies de animais e plantas. No lado oposto, uma bancada comprida expõe diversos equipamentos e instrumentos físico-químicos, escondendo o almoxarifado onde ficavam os materiais e componentes químicos.

Para iniciar a aula, os alunos e alunas se dirigiam do prédio dos anos iniciais do Ensino Fundamental, para o laboratório de química acompanhados de ao menos uma das professoras. Ao chegarem na sala os estudantes eram convidados e colocar suas mochilas e lancheiras sob uma das bancadas e se direcionar para a mesa de centro onde as professoras os aguardavam com o material para a experiência da manhã. Ao início de todas as aulas ocorriam conversas descontraídas com os alunos, oferecendo liberdade para eles se expressarem e assim termos a oportunidade de mapear seus interesses, como filmes, séries, desenhos e experiências que eles gostariam de fazer na oficina.

Após a explicação da atividade, os estudantes começavam os trabalhos, normalmente no grande grupo ou em grupos menores para trabalhar a convivência e relação entre as diferentes séries e idades.

As experiências que foram realizadas eram testadas antes das aulas para garantir a segurança dos estudantes. Alguns dos experimentos realizados foram: "vulcão de bicarbonato de sódio e vinagre", "vulcão submarino", "slime”, “águas que andam”, "mensagem secretas” e "sangue de unicórnio". Ao final das aulas, os alunos eram convidados a fazer o registro das atividades que foram realizadas na manhã, se expressando da forma como eles achavam mais confortável no papel, pedindo ajuda sempre que necessário.

Nosso último encontro foi na Mostra, que encerrou as atividades da oficina "Fazendo Arte e Aprendendo Ciências". Esse era o evento mais esperado pelos participantes da oficina, pois constava da participação de familiares e amigos convidados. O evento ocorre para que os alunos possam trocar as experiências que obtiveram durante o semestre nas disciplinas eletivas. As oficinas trabalhavam diversos conteúdos e abordavam de diversas formas o mesmo tema com os estudantes: meio ambiente, alimentação, diversidade cultural pelo mundo, plantas e ciências. Todas essas abordagens estavam presentes nessa atividade institucional. E para isso a turma foi dividida em dois grupos, enquanto um grupo estava apresentando, os demais estavam visitando os outros estandes.

A Mostra ocorreu da seguinte forma: as salas de aula dos anos iniciais do Ensino Fundamental foram separadas cada uma atendendo duas oficinas. A sala foi organizada no período do recreio, onde as mesas foram colocadas em formato "L" e seus trabalhos artísticos expostos em um varal com prendedores, logo atrás uma mesa onde cuidadosamente as experiências foram posicionadas. Cada aluno ficou responsável de apresentar uma experiência e em nenhum momento foi tomada às explicações, os estudantes utilizaram-se de suas próprias palavras para explicar e responder seus colegas. As experiências que foram apresentadas, foram escolhidas pelos alunos na aula anterior e quem apresentaria cada uma delas.

\section{Referencial teórico}

As produções artísticas dos alunos ao final da aula e os diários das "pibidianas”, com anotações e relatos realizados manualmente, se tornaram um repositório das atividades dos alunos. Pois é uma habilidade, sendo uma arte utilitária, para a pessoa que o está criando, por ser proveitosos no seu dia a dia, se tornando uma arte decorativa após sua finalização, cuja razão é sua beleza e conteúdo. O consumidor dessa arte sente algo provocado pelo artista, como defende Carvalho e Quintela (1991). Vários especialistas na área da educação e da psicologia, defendem que os professores devem buscar aprimorar a competência dos alunos nas diferentes modalidades de registro, sobretudo daqueles que trabalham com as crianças das séries iniciais, ainda pouco familiarizadas com o método científico, como defendido por Polato (2011). 
Conforme Fontana (2005) quando nossa realidade é confrontada os saberes que temos sofrem uma mudança bem significativa. A prática de sala aula nos faz repensar nossa visão de mundo, nos alunos que estamos formando, quais serão seus princípios e propósitos, que tipo de professor estamos nos formando e como é e será nossa prática em sala de aula e a partir daí percebemos como nossa ação está atuando de diferentes formas nos alunos e alunas. "As melhores emoções da nossa natureza são sentidas, analisadas e entendidas, mais profundamente na maturidade, mas elas nascem e se manifestam com plena intensidade durante a nossa infância e a adolescência. Depois durante o resto de nossas vidas, servindo como fonte de trabalho criativo" (WILSON, 2015, p. 45).

Sendo mais sensíveis ao mundo, crianças e pré-adolescentes criaram uma arte sincera, tendo-se aí um registro puro e genuíno dos seus sentimentos. E assim, os registros, feitos das mais diversas formas, são uma ferramenta para eternizar os momentos e realizações na infância e tornasse uma forma de analisar o adulto que está se formando. Portanto o incentivo à produção artística do aluno é de suma importância, pois provoca o desenvolvimento motor, criativo, descritivo e de análise e é indispensável ao se pensar qual o sujeito que está em formação.

Seguindo a linha, a oficina buscou contribuir com os conhecimentos prévios dos alunos e dentro das suas realidades e interesses. Pensando em contribuir na formação de estudantes mais curiosos e capacitados dentro da sua formação escolar.

\section{Análise dos resultados}

As conversas iniciais com os alunos antes das aulas, em especial, no primeiro encontro, possibilitaram verificar a relação já existente entre a arte e os estudantes. Nas conversas, seus filmes, séries, histórias e desenhos oportunizaram conversas animadas que nos auxiliaram a mapear as possíveis experiências que cairiam no gosto dos alunos. Essa conversa nos permitiu identificar as formas de arte que os alunos estão mais familiarizados e nos possibilitou associar seus gostos ao tema das atividades.

A partir das atividades lúdicas envolvendo arte foi possível apresentar os conceitos científicos de forma mais leve e fluída, assim os alunos foram criando hipóteses e teorias para o que estava acontecendo nos experimentos, fazendo-os pensarem e refletirem de forma independente e coletiva ao mesmo tempo sobre o desconhecido, tornando a atividade mais atrativa. A arte foi representada das mais diversas formas pelos estudantes e nos cadernos das bolsistas "pibidianas". Desde a escolha das cores dos experimentos, os instrumentos utilizados para realização das atividades, os desenhos, a forma de registro escrito, com cores, fontes e formato textual, o trabalho em equipe e aprender a compartilhar os materiais.

A arte estava presente nos desenhos, escritas, fala e expressões faciais e gestos dos alunos durante as práticas da oficina. A utilização da arte para ensinar conceitos das Ciências da Natureza se mostrou eficiente ao longo de todo o semestre. Ao surgir dificuldades na fala, os alunos utilizavam da sua criatividade no papel para representar o que estavam compreendendo. Todos os trabalhos realizados foram expostos no dia da Mostra, os educandos mostraram orgulhosos para seus familiares tudo o que realizaram.

\section{Considerações finais}

A análise dos registros possibilitou a verificação da interação de todos os alunos com as atividades propostas, já que eram feitas individualmente, como também, diferentes formas de aprendizado e conhecimentos foram observadas. Alguns alunos avançaram no desenvolver da escrita, na motricidade e na pronúncia de fonemas que eram difíceis no início das atividades. A Mostra ainda foi um resultado do processo de aprendizado dos alunos e alunas, pois reforçaram todos os conhecimentos adquiridos por eles. Antes das apresentações dos trabalhos na Mostra, não foram feitas revisões das experiências, então os alunos 
e alunas se expressaram e apresentaram aquilo que realmente aprenderam. Estudantes de 10 anos souberam explicar o conceito de "polar" e "apolar", condição química referente à eletronegatividades das moléculas.

A oficina eletiva "Fazendo Arte e Aprendendo Ciências" foi de grande valia para a formação das "pibidianas" como professoras. O reconhecimento de ser professora tornou-se perceptível para elas ao longo de todo processo da oficina. Respeitar o tempo de aprendizagem dos alunos e alunos e a busca por contribuir com o seu conhecimento prévio e formar sujeitos donos do seu conhecimento e protagonistas de suas vidas foram seus grandes empecilhos vencidos no processo. O ensino diferenciado e interdisciplinar dentro das ciências possibilitou para as estudantes colocarem em prática o que estavam aprendendo na graduação e se desafiarem ainda mais para isso ocorrer.

Essa oportunidade que o PIBID proporcionou formou novas professoras com visões mais apuradas em sala de aula, vivências construtivas e com diversidade de abordagem em sala de aula. Pensar "fora da caixa" dentro da educação tem sido cada vez mais solicitado e desafiador, assim o PIBID auxiliou na formação de educadoras com ideias inovadoras e únicas.

\section{Referências}

CARVALHO, André; QUINTELlA, Ary. Arte. Belo Horizonte: Lê, 1991. (Coleção Pergunte ao José).

COORDENAÇÃO DE APERFEIÇOAMENTO DE PESSOAL DE NÍVEL SUPERIOR (CAPES). Pibid - Programa Institucional de Bolsa de Iniciação à Docência. Brasília, DF: CAPES, 2020. Disponível em: http://uab.capes.gov.br/educacao-basica/ capespibid/pibid. Acesso em: 30 dez. 2020.

FONTANA, Roseli A. Cação. Como nos tornamos professoras? 3. ed. Belo Horizonte: Autêntica, 2005.

LEWGOY, Alzira Maria Baptista; ARRUDA, Maria. Novas tecnologias na prática profissional do professor universitário: a experimentação do diário digital. Revista Texto \& Contextos, Porto Alegre, v. 1, n. 2, p. 115-130, 2004.

POLATO, Amanda. A importância do registro em Ciências. Nova Escola, São Paulo, 1 fev. 2011. Disponível em: https://novaescola.org.br/conteudo/1114/a-importancia-do-registro-em-ciencias\#\%3E. Acesso em: 21 jan. 2020.

VALLADARES, Licia. Os dez mandamentos da observação participante. Revista Brasileira de Ciências Sociais, São Paulo, v. 22, n. 63, p. 153 - 155, 2007.

WILSON, Eduardo. Cartas a um jovem cientista. 1. ed. São Paulo: Companhia das Letras, 2015.

Data de submissão: 19/06/2020

Data de aceite: $22 / 07 / 2020$ 